\title{
Article \\ Changes in Muscle Activity Imbalance of the Lower Limbs Following 3 Weeks of Supplementary Body-Weight Unilateral Training
}

\author{
Sylwia Mrzygłód, Przemysław Pietraszewski * (D), Artur Golas (D), Jakub Jarosz (D), Aleksander Matusiński \\ and Michał Krzysztofik
}

check for

updates

Citation: Mrzygłód, S.; Pietraszewski, P.; Golas, A.; Jarosz, J.; Matusiński, A.; Krzysztofik, M. Changes in Muscle Activity Imbalance of the Lower Limbs Following 3 Weeks of Supplementary Body-Weight Unilateral Training. Appl. Sci. 2021, 11, 1494. https://doi.org/ 10.3390/app11041494

Academic Editors: Mark King and Redha TAIAR

Received: 25 December 2020

Accepted: 1 February 2021

Published: 7 February 2021

Publisher's Note: MDPI stays neutral with regard to jurisdictional claims in published maps and institutional affiliations.

Copyright: (c) 2021 by the authors. Licensee MDPI, Basel, Switzerland. This article is an open access article distributed under the terms and conditions of the Creative Commons Attribution (CC BY) license (https:// creativecommons.org/licenses/by/ $4.0 /)$.
Institute of Sport Sciences, The Jerzy Kukuczka Academy of Physical Education, 40-065 Katowice, Poland; s.mrzyglod@awf.katowice.pl (S.M.); a.golas@awf.katowice.pl (A.G.); j.jarosz@awf.katowice.pl (J.J.); a.matusinski@awf.katowice.pl (A.M.); m.krzysztofik@awf.katowice.pl (M.K.)

* Correspondence: p.pietraszewski@awf.katowice.pl

\begin{abstract}
This study examined the effects of a short-term supplementary body-weight training program on changes in the muscle activity imbalance of the lower limbs during high-speed running in soccer players. Fifteen professional male soccer players took part in the study (age: $25 \pm 5$ years, body mass: $79.2 \pm 10.8 \mathrm{~kg}$, stature: $177 \pm 10 \mathrm{~cm}$, training experience: $12 \pm 5$ years). The evaluations of lower limb muscle activity imbalance via surface electromyography (sEMG) were performed twice (pre- and post-intervention), at a three-week interval. The sEMG was measured bilaterally from the area of quadriceps $(\mathrm{Q})$, hamstrings $(\mathrm{H})$, and gluteal muscles $(\mathrm{G})$ during high-speed running at $18 \mathrm{~km} / \mathrm{h}$ using sEMG shorts. Between measurements, the athletes performed the supplementary body-weight program of the lower limbs 4 times a week for 3 weeks. The training included six body-weight exercises performed unilaterally. The load progression included an additional set of each exercise in successive weeks of the experiment. The two-way repeated-measures ANOVA indicated a statistically significant main interaction for time $\times$ muscle $\left(p=0.006 ; \mathrm{F}=6.948 ; \eta^{2}=0.332\right)$. The post-hoc analysis for the interaction effect of time $\times$ muscle showed a statistically significant decrease in muscle imbalance for the post-intervention compared to the pre-intervention for the $\mathrm{H}$ $(p<0.001 ; \mathrm{ES}=1.32), \mathrm{G}(p=0.002 ; \mathrm{ES}=0.92)$, and $\mathrm{T}(p<0.001 ; \mathrm{ES}=1.54)$, but not for $\mathrm{Q}(p=0.56 ;$ ES $=0.14)$. Moreover, there was a statistically significant greater imbalance between the $H, G$, and $\mathrm{T}$ muscles versus $\mathrm{Q}(p=0.043, \mathrm{ES}=1.15 ; p=0.006, \mathrm{ES}=1.57 ; p=0.001, \mathrm{ES}=1.69$, respectively $)$ for the values recorded pre-intervention. Changes in muscle activity after 3 weeks of sports-specific movement patterns were statistically significant. For the gluteal $(\mathrm{G})$ and hamstring $(\mathrm{H})$, the imbalance between the limbs decreased significantly $(p=0.01)$. The imbalance in the quadriceps muscles $(Q)$, with respect to each limb, did not decrease significantly $(p=0.82)$ following the training intervention. Conclusions: The results of this study indicate that in-season soccer training supplemented with a body-weight training program successfully decreases gluteal and hamstring imbalance between limbs after 3 weeks of training.
\end{abstract}

Keywords: soccer; EMG; running speed; muscle patterns; strength

\section{Introduction}

The injury rates in soccer are steadily increasing [1]. Players often show an uneven development of the right and left limbs due to the technical elements performed during competition and training, which can cause functional or even structural asymmetry. The imbalance between limbs, e.g., the dominance of one side of the body over the other, may result in differences in the strength of particular muscle groups. Studies of soccer players have shown differences in strength and flexibility between the dominant and nondominant limbs [2], and the biomechanical asymmetries between each limb [3]. It has been proven that muscle strength deficiencies and asymmetries of lower limb muscles increase 
the risk of thigh muscle injury [4]. Ekstrand et al. [5] documented a $4 \%$ annual increase in femoral tendon injuries in European soccer league players in 2001-2014. Currently, $22 \%$ of players suffer from at least one femoral tendon injury during a season. The risk factors commonly seen as predictive for knee or femoral joint injuries include a decreased hamstring/quadriceps ratio $(\mathrm{H} / \mathrm{Q})$ and a bilateral strength deficit, as well as the weakness of lower limb muscles [6,7]. Functional asymmetry of the lower limbs (side-to-side asymmetry) greater than $15 \%$ [1,8] may increase the risk of knee injuries [1,9].

Surface electromyography (sEMG) is a diagnostic tool in the field of clinical neurophysiology used to analyze the function of the motor entities of a selected muscle or muscle group by means of surface electrodes during exercise or at rest [10]. The data collected from sEMG analysis provide information about the magnitude of activation for a given muscle [11] and how much work or effort in a muscle is needed to perform a certain task [12], which might be useful in sports performance development and injury prevention [11,13-17]. Therefore, the utilization of sEMG data, together with the measurement of physical fitness, is often used to assess the effectiveness and suitability of using specific conditions [18,19], short- [20,21], and long-term interventions $[15,22,23]$ in sports training. However, depending on the experience of the participants in resistance training, the adaptations may vary slightly. In the case of untrained participants, with increasing physical fitness due to performed training, muscle activity also increases [20]. On the other hand, in experienced participants, the improvement in performance may be due to a change in the muscle activity pattern rather than to its increase itself [15]. For example, Saeterbakken et al. [20] found an increase in quadriceps muscle activity after 3 weeks of squat exercise training, along with improvements in maximum muscle strength and countermovement jump performance in participants who did not perform lower limb training regularly. However, in a study by Marshall et al. [22], the increase in maximum muscle strength was not associated with an increase in the muscle activity of the quadriceps muscles in resistance-trained participants. Moreover, the study by Strońska et al. [15] also showed no increase in muscle activity, but a change in its pattern which was noted with an increase in the one-repetition maximum during bench press after targeted resistance training in resistance-trained participants. Therefore, it can be assumed that reducing the deficiency or/and imbalance in muscle activity may be a useful method for improving sports performance and, potentially, injury prevention [11,13-17].

Consequently, the aim of this study was to investigate the changes in the muscle activity during running after a short-duration supplementary body-weight training program in professional soccer players. Since previous research has shown that the pattern of muscle activity can change with the training performed [15], we hypothesized that 3-weeks of the supplementary body-weight program would be sufficient to decrease the muscle imbalance between lower limbs.

\section{Materials and Methods}

\subsection{Participants}

Fifteen professional soccer players took part in the study (age: $25 \pm 5$ years, body mass: $79.2 \pm 10.8 \mathrm{~kg}$, stature: $177 \pm 10 \mathrm{~cm}$, training experience: $12 \pm 5$ years). All participants had valid medical examinations and showed no contraindications to participate in physical fitness tests. The experimental sessions took place during the in-season period, with the participants training 5-6 times per week, each session lasting between 60 and $90 \mathrm{~min}$. The participants were instructed to maintain their normal dietary habits over the course of the study and not to use any stimulants for the duration of the experiment. The participants did not perform any strenuous exercises $48 \mathrm{~h}$ prior to testing to avoid fatigue. The participants were informed verbally and in writing about the procedures and the possible risks and benefits of the tests and provided written consent before the start of the study. The study received the approval of the Bioethics Committee at the Academy of Physical Education in Katowice, Poland. 


\subsection{Procedures}

The measurements were performed in the Strength and Power Laboratory of the Jerzy Kukuczka Academy of Physical Education in Katowice, Poland. The evaluations were performed twice, at a three-week interval. During this period, the participants performed the supplementary body-weight training program 4 times per week for 3 weeks (Monday, Tuesday, Thursday, Friday). The training included 6 body-weight exercises (Bird Dog, Glute Bridge Single-Leg Progression, Dead Bug, Side Plank, Reverse Lunge and Clamshell), performed unilaterally in 3-5 sets of 10 repetitions of each exercise with $60 \mathrm{~s}$ rest intervals between sets. The training volume progression included an additional set in each successive week of the experiment, from 3 sets in the first week to 5 sets in the third week. These exercises were chosen because their execution was well- known to participants and they largely engage the muscles that are most active during high-speed running [24]. The sEMG data were collected during two $10 \mathrm{~s}$ runs (separated by a 1 min rest) at a speed of $18 \mathrm{~km} / \mathrm{h}$ on a treadmill (Matrix T5X) at baseline and after 3 weeks of training. This treadmill running speed was chosen since it was considered as the low range value of a high-speed running zone in previous studies in soccer players [25-27] and was well tolerated by all participants of this study. A standardized warm-up preceded testing that included $10 \mathrm{~min}$ of jogging, followed by 2 short accelerations $(20 \mathrm{~m})$ and dynamic stretching for the major muscle groups.

\subsection{Electromyography}

sEMG was measured bilaterally from the $\mathrm{Q}, \mathrm{H}$, and $\mathrm{G}$ muscles with shorts made of knitted fabric similar to elastic clothes used for sports activities or functional underwear, with the exception of the possibility to measure sEMG from the skin surface (Myontec Ltd., Kuopio and Suunto Ltd., Vantaa, Finland). The bipolar electrode pairs are embedded onto the internal surface of shorts and measure the average rectified sEMG signal, on the distal part of the $Q, H, G$, and the reference electrodes are located longitudinally along the left and right lateral sides (over the tractus iliotibialis) providing valid and repeatable data [28-30]. However, it should be emphasized that they are unable to measure specific muscles (e.g., vastus lateralis) within the overall muscle group (e.g., quadriceps). The electrodes located on the $\mathrm{Q}$ muscles area collected data from the vastus lateralis, vastus medialis, and rectus femoris muscles. The vastus intermedius muscle is located deeply under the other muscles and thus was not included. The electrodes located on the $\mathrm{H}$ muscles area gathered the signal from the biceps femoris, semimembranosus, and semitendinosus muscles. The electrodes located on the $G$ muscles area recorded signals from the gluteus maximus and gluteus medius muscles. The sEMG signals were measured in a raw form with a sampling frequency of $1000 \mathrm{~Hz}$ and a frequency band of $50 \mathrm{~Hz}-200 \mathrm{~Hz}(-3 \mathrm{~dB})$. The raw sEMG signals were first rectified and then averaged over each $100 \mathrm{~ms}$ interval without overlapping. Therefore, 10 consecutive samples from the raw signal formed one rectified averaged data sample. These $10 \mathrm{~Hz}$ data were stored in ASCII format in the module memory, uploaded to the PC using custom software. From the $10 \mathrm{~Hz}$ sEMG data, the average rectified value was calculated from a $1 \mathrm{~s}$ window during a stable torque signal. Six channels (three from each leg) were recorded. To ensure proper signal conduction, the electrodes were moisturized with tap water before putting on the shorts. When wetted, a membrane covering the electrodes prevents the electrode-skin interface from drying. The average muscle activity imbalance between the lower limbs for each muscle group was used for further analysis.

\subsection{Statistical Analysis}

All calculations were performed using SPSS (version 25.0; SPSS, Inc., Chicago, IL, USA) and were expressed as means with standard deviations ( \pm SD). Statistical significance was set at $p<0.05$. The normality of data distribution was checked using Shapiro-Wilk tests. Due to the normal distribution of all analyzed data, the percentage of changes in muscle activity imbalance between the lower limbs for each muscle group $(Q ; H ; G)$ and 
total muscle activity $(\mathrm{T})$ was analyzed with a two-way $(2 \times 4)$ ANOVA with repeated measures. Effect sizes for main effects and interaction were estimated by calculating the partial eta squared $\left(\eta^{2}\right)$. In the event of a significant main effect, post-hoc comparisons were conducted using the Bonferroni test. Mauchly's test of sphericity was conducted to test for the homogeneity of data and if violated $(p<0.05)$, the Greenhouse-Geisser adjustment value was used. The $95 \%$ confidence intervals were also calculated. Effect sizes (ES, Cohen's d) were reported and were defined as large $\mathrm{d}>0.8$; moderate between 0.79 and 0.5 ; small between 0.49 and 0.20 ; and trivial as $<0.2$ [31].

\section{Results}

The two-way repeated-measures ANOVA indicated a statistically significant main interaction for time $\times$ muscle $\left(p=0.006 ; \mathrm{F}=6.948 ; \eta^{2}=0.332\right)$. A statistically significant main effect for muscle $\left(p=0.009 ; \mathrm{F}=6.772 ; \eta^{2}=0.326\right)$ and time $(p<0.001 ; \mathrm{F}=43.030$; $\left.\eta^{2}=0.755\right)$ was also observed.

The post-hoc analysis for the interaction effect of time $\times$ muscle showed a statistically significant decrease in muscle activity imbalance for the post-intervention compared to the pre-intervention for $\mathrm{H}(p<0.001 ; \mathrm{ES}=1.32), \mathrm{G}(p=0.002 ; \mathrm{ES}=0.92)$ and $\mathrm{T}(p<0.001$; $\mathrm{ES}=1.54)$, but not for $\mathrm{Q}(p=0.56$; $\mathrm{ES}=0.14)$. Moreover, there was a statistically significant greater imbalance between the H, G, T muscles versus the Q muscles $(p=0.043$, $\mathrm{ES}=1.15 ; p=0.006, \mathrm{ES}=1.57 p=0.001, \mathrm{ES}=1.69$, respectively) for the values recorded pre-intervention. However, there were no statistically significant differences in muscle activity imbalance between the other comparisons within pre- or post-intervention values (Table 1).

Table 1. Difference in muscle activity imbalance between and within pre- and post-intervention for the quadriceps $(Q)$, hamstrings $(H)$, gluteal muscles $(G)$, and for the total activity of these muscles $(T)$.

\begin{tabular}{cccccc}
\hline \multirow{2}{*}{ Muscle [\%] } & \multicolumn{2}{c}{ Pre-Intervention } & \multicolumn{2}{c}{ Post Intervention } & \multirow{2}{*}{ ES } \\
\cline { 2 - 5 } & Mean \pm SD & $\pm \mathbf{9 5 \%}$ CI & Mean $\pm \mathbf{S D}$ & $\pm \mathbf{9 5 \%}$ CI & \\
\hline Q & $8.13 \pm 3.8$ & $6.03-10.23$ & $7.6 \pm 3.68$ & $5.56-9.64$ & 0.14 \\
H & $17.07 \pm 10.35 \#$ & $11.34-22.8$ & $6.47 \pm 4.69 *$ & $3.87-9.06$ & 1.32 \\
G & $21.53 \pm 11.42 \#$ & $15.21-27.86$ & $12.13 \pm 8.8 *$ & $7.26-17.01$ & 0.92 \\
T & $15.67 \pm 5.02 \#$ & $12.88-18.45$ & $8.67 \pm 4.03 *$ & $6.43-10.9$ & 1.54 \\
\hline
\end{tabular}

Quadriceps muscles $(\mathrm{Q})$, hamstring muscles $(\mathrm{H})$, gluteal muscles $(\mathrm{G})$, total activity $(\mathrm{T})$; SD—standard deviation CI - confidence interval; ES - effect size; * significant difference between pre- and post-intervention values $p<0.05$; \# significant difference within recorded muscle activity values $p<0.05$.

\section{Discussion}

The main finding of this study was that 3-weeks of the supplementary body-weight training program performed along with soccer training during the season were effective in decreasing lower limb muscle activity imbalance during high-speed running in professional soccer players. The statistically significant decrease in imbalances was found in the hamstring and gluteal muscles in comparison to baseline values. To the authors' knowledge, this is the first study to examine a short-term supplementary body-weight training program performed during the competitive season in professional soccer players. Considering that there was no control group in the study, it cannot be confidently stated that the results are related to the performed supplementary body-weight training program and not to the soccer training itself. Nevertheless, significant knowledge for future research and training clues can be derived from the current data.

The fact that a very short-term (3 weeks) supplementary body-weight training program performed along with soccer training during the season was so effective in decreasing the muscle activity imbalance of the lower limbs during high-speed running in professional soccer players is of high practical value. This is because in most professional sports, coaches have to allocate the necessary time to improve technical skills, team tactics, and physical fitness. Moreover, the training regimen presented in this study does not require any spe- 
cialized equipment requirements. Taking this into account, a short-term, supplementary body-weight training program such as the one used in the present study would offer an efficient way to improve lower limb muscle activity balance during running with a minimal time and equipment investment.

Significant imbalances between the right and left lower limbs are caused by the differences in the strength of particular muscle groups. The dominance of one side of the body over the other causes differences in the strength of various muscles activated during specific actions required in the sport. Studies of soccer players have shown differences in strength and flexibility between the dominant and non-dominant limbs [2] and biomechanical asymmetries between each other [3]. It has been proven that muscle strength deficiencies and asymmetries in the lower limbs increase the risk of thigh muscle injuries [4]. Daneshjoo et al. [32] attempted to define whether strength and flexibility asymmetries were present in the legs of soccer players. They found significant differences between the dominant and non-dominant limbs in the knee flexors and for the dynamic control ratio. In both cases, the knee flexors of the preferred leg were weaker than those of the non-preferred leg. Almost $68 \%$ of players had significant musculoskeletal abnormalities (imbalance $>10 \%$ ) in one or more muscle groups, while no significant differences were found in the flexibility of the hip joint between the preferred and non-preferred leg [33].

In the present study, a 3-week soccer training supplemented with a body-weight training program had a statistically significant effect on the reduction of the disproportions in $\mathrm{H}, \mathrm{G}$, and $\mathrm{T}$, which may translate into a reduction of injury risk. A decreasing asymmetry was observed for the $Q$ muscles, but the changes were not statistically significant, due to the exercises performed in the training regimen, in which the $Q$ muscles were not as involved as $\mathrm{G}$ or $\mathrm{H}$. The literature on muscle activity during running lacks data on the changes in the pattern of muscle activity following a specific period of supplementary training programs, whereas no data exist on the changes of these patterns at different levels of external loads [33]. Furthermore, no studies have demonstrated differences in the activity of particular muscles and their comparison with each other. Comparisons of overall muscle activity of the right and left limbs often fail to show disproportions, whereas analysis of particular muscles with respect to each other (Q-Q, H-H, G-G) reveals significant statistical differences [34]. This may result from the fact that the central nervous system compensates for the disturbances in the activity of particular muscles by transferring part of the load to other muscles. Consequently, the activity of the right lower limb can be taken over and controlled by a different muscle than in the left limb. Training based on movement patterns and activation of particular muscles can reduce the disproportion of $(\mathrm{Q}-\mathrm{Q}, \mathrm{H}-\mathrm{H}, \mathrm{G}-\mathrm{G})$ with respect to each other.

This study has several limitations, which have to be addressed. The main limitation concerns the lack of a control group, so it cannot be definitely stated that the reduced imbalance is a result of the supplementary body-weight training program. In addition, it cannot be excluded that muscle activity imbalance during linear running at higher velocities (e.g., $>18 \mathrm{~km} / \mathrm{h}$ ) would have been improved, as well as running with a change of direction. Another limitation of this study was that the muscle activity was recorded only during treadmill running, which does not have to translate into running on the field. In addition, no kinematic variables were measured, which means that the decrease in lower limb muscle activity imbalance does not have to improve high-speed running performance. Furthermore, it should be taken into account that the participants of this study were highly trained and the results of this study should not be replicated in groups with lower training experience. Future studies should assess whether the reduction of imbalance in lower limb muscle activity contributes to the improvement of high-speed running performance. Moreover, it would be interesting to assess whether the obtained reduction of imbalance persists for a longer time, despite the cessation of the supplementary body-weight training program. 


\section{Conclusions}

The results suggest that in-season soccer training supplemented with a body-weight training program provides an effective method for improving lower limb muscle activity balance during high-speed running in elite soccer players. Coaches and practitioners should consider assessing lower limb muscle imbalances in soccer players and adjust the additional supplementary training programs accordingly to reduce them, which may prevent injury.

Author Contributions: Conceptualization, S.M. and A.G.; methodology, A.G. and P.P.; formal analysis, S.M., A.G. and P.P.; investigation, J.J. and A.M.; writing—original draft preparation, A.M. and M.K.; writing - review and editing, M.K. and P.P.; project administration, S.M. and A.G. All authors have read and agreed to the published version of the manuscript.

Funding: This research received no external funding.

Institutional Review Board Statement: The research was approved by the Ethics Committee of The Academy of Physical Education in Katowice (10/2018) and executed according to the ethical standards of the latest version of the Declaration of Helsinki, 2013.

Informed Consent Statement: Informed consent was obtained from all subjects involved in the study.

Data Availability Statement: Academy of Physical Education in Katowice, 40-065, Poland.

Conflicts of Interest: The authors declare no conflict of interest.

\section{References}

1. Van Dyk, N.; Bahr, R.; Whiteley, R.; Tol, J.L.; Kumar, B.D.; Hamilton, B.; Farooq, A.; Witvrouw, E. Hamstring and Quadriceps Isokinetic Strength Deficits Are Weak Risk Factors for Hamstring Strain Injuries: A 4-Year Cohort Study. Am. J. Sports Med. 2016, 44, 1789-1795. [CrossRef]

2. Scilingo, E.P.; Gemignani, A.; Paradiso, R.; Taccini, N.; Ghelarducci, B.; DeRossi, D. Performance Evaluation of Sensing Fabrics for Monitoring Physiological and Biomechanical Variables. IEEE Trans. Inf. Technol. Biomed. 2005, 9, 345-352. [CrossRef]

3. Dörge, H.C.; Andersen, T.B.; SØrensen, H.; Simonsen, E.B. Biomechanical Differences in Soccer Kicking with the Preferred and the Non-Preferred Leg. J. Sports Sci. 2002, 20, 293-299. [CrossRef] [PubMed]

4. Croisier, J.-L.; Ganteaume, S.; Binet, J.; Genty, M.; Ferret, J.-M. Strength Imbalances and Prevention of Hamstring Injury in Professional Soccer Players: A Prospective Study. Am. J. Sports Med. 2008, 36, 1469-1475. [CrossRef] [PubMed]

5. Ekstrand, J.; Waldén, M.; Hägglund, M. Hamstring Injuries Have Increased by $4 \%$ Annually in Men's Professional Football, since 2001: A 13-Year Longitudinal Analysis of the UEFA Elite Club Injury Study. Br. J. Sports Med. 2016, 50, 731-737. [CrossRef]

6. Alentorn-Geli, E.; Myer, G.D.; Silvers, H.J.; Samitier, G.; Romero, D.; Lázaro-Haro, C.; Cugat, R. Prevention of Non-Contact Anterior Cruciate Ligament Injuries in Soccer Players. Part 1: Mechanisms of Injury and Underlying Risk Factors. Knee Surg. Sports Traumatol. Arthrosc. 2009, 17, 705-729. [CrossRef] [PubMed]

7. Hughes, P.C.; Green, R.A.; Taylor, N.F. Isolation of Infraspinatus in Clinical Test Positions. J. Sci. Med. Sport 2014, 17, $256-260$. [CrossRef]

8. Croisier, J.-L.; Forthomme, B.; Namurois, M.-H.; Vanderthommen, M.; Crielaard, J.-M. Hamstring Muscle Strain Recurrence and Strength Performance Disorders. Am. J. Sports Med. 2002, 30, 199-203. [CrossRef]

9. Kiesel, K.B.; Butler, R.J.; Plisky, P.J. Prediction of Injury by Limited and Asymmetrical Fundamental Movement Patterns in American Football Players. J. Sport Rehabil. 2014, 23, 88-94. [CrossRef]

10. Pope, G.D. Introduction to Surface Electromyography. Physiotherapy 1998, 84, 405. [CrossRef]

11. Stastny, P.; Tufano, J.J.; Golas, A.; Petr, M. Strengthening the Gluteus Medius Using Various Bodyweight and Resistance Exercises. Strength Cond. J. 2016, 38, 91-101. [CrossRef] [PubMed]

12. Tikkanen, O.; KäRKKäINEN, S.; Haakana, P.; Kallinen, M.; Pullinen, T.; Finni, T. EMG, Heart Rate, and Accelerometer as Estimators of Energy Expenditure in Locomotion. Med. Sci. Sports Exerc. 2014, 46, 1831-1839. [CrossRef] [PubMed]

13. Howard, R.M.; Conway, R.; Harrison, A.J. Muscle Activity in Sprinting: A Review. Sports Biomech. 2018, 17, 1-17. [CrossRef] [PubMed]

14. Serner, A.; Jakobsen, M.D.; Andersen, L.L.; Hölmich, P.; Sundstrup, E.; Thorborg, K. EMG Evaluation of Hip Adduction Exercises for Soccer Players: Implications for Exercise Selection in Prevention and Treatment of Groin Injuries. Br. J. Sports Med. 2014, 48, 1108-1114. [CrossRef] [PubMed]

15. Stronska, K.; Golas, A.; Wilk, M.; Zajac, A.; Maszczyk, A.; Stastny, P. The Effect of Targeted Resistance Training on Bench Press Performance and the Alternation of Prime Mover Muscle Activation Patterns. Sports Biomech. 2020, 1-15. [CrossRef] [PubMed]

16. Stastny, P.; Lehnert, M.; Tufano, J.J. Muscle Imbalances: Testing and Training Functional Eccentric Hamstring Strength in Athletic Populations. J. Vis. Exp. 2018, 135, 57508. [CrossRef] 
17. Stastny, P.; Lehnert, M.; Zaatar, A.; Svoboda, Z.; Xaverova, Z.; Jelen, K. Knee Joint Muscles Neuromuscular Activity during Load-Carrying Walking. Neuro Endocrinol. Lett. 2014, 35, 633-639.

18. Krzysztofik, M.; Golas, A.; Wilk, M.; Stastny, P.; Lockie, R.G.; Zajac, A. A Comparison of Muscle Activity Between the Cambered and Standard Bar During the Bench Press Exercise. Front. Physiol. 2020, 11, 875. [CrossRef]

19. Krzysztofik, M.; Jarosz, J.; Matykiewicz, P.; Wilk, M.; Bialas, M.; Zajac, A.; Golas, A. A Comparison of Muscle Activity of the Dominant and Non-Dominant Side of the Body during Low versus High Loaded Bench Press Exercise Performed to Muscular Failure. J. Electromyogr. Kinesiol. 2021, 56, 102513. [CrossRef]

20. Saeterbakken, A.H.; Olsen, A.; Behm, D.G.; Bardstu, H.B.; Andersen, V. The Short- and Long-Term Effects of Resistance Training with Different Stability Requirements. PLOS ONE 2019, 14, e0214302. [CrossRef]

21. Buckthorpe, M.; Erskine, R.M.; Fletcher, G.; Folland, J.P. Task-Specific Neural Adaptations to Isoinertial Resistance Training: Neural Adaptations to Resistance Training. Scand. J. Med. Sci. Sports 2015, 25, 640-649. [CrossRef]

22. Marshall, P.W.M.; McEwen, M.; Robbins, D.W. Strength and Neuromuscular Adaptation Following One, Four, and Eight Sets of High Intensity Resistance Exercise in Trained Males. Eur. J. Appl. Physiol. 2011, 111, 3007-3016. [CrossRef]

23. Saeterbakken, A.H.; Andersen, V.; Behm, D.G.; Krohn-Hansen, E.K.; Smaamo, M.; Fimland, M.S. Resistance-Training Exercises with Different Stability Requirements: Time Course of Task Specificity. Eur. J. Appl. Physiol. 2016, 116, 2247-2256. [CrossRef] [PubMed]

24. Novacheck, T.F. The Biomechanics of Running. Gait Posture 1998, 7, 77-95. [CrossRef]

25. Gimenez, J.V.; Jimenez-Linares, L.; Garcia-Unanue, J.; Sanchez-Sanchez, J.; Gallardo, L.; Felipe, J.L. Analyse Success Model of Split Time and Cut-Off Point Values of Physical Demands to Keep Category in Semi-Professional Football Players. Appl. Sci. 2020, 10, 5299. [CrossRef]

26. García-Unanue, J.; Pérez-Gómez, J.; Giménez, J.-V.; Felipe, J.L.; Gómez-Pomares, S.; Gallardo, L.; Sánchez-Sánchez, J. Influence of Contextual Variables and the Pressure to Keep Category on Physical Match Performance in Soccer Players. PLoS ONE 2018, 13, e0204256. [CrossRef]

27. Casamichana, D.; Castellano, J.; Calleja-Gonzalez, J.; San Román, J.; Castagna, C. Relationship Between Indicators of Training Load in Soccer Players. J. Strength Cond. Res. 2013, 27, 369-374. [CrossRef] [PubMed]

28. Tikkanen, O.; Haakana, P.; Pesola, A.J.; Häkkinen, K.; Rantalainen, T.; Havu, M.; Pullinen, T.; Finni, T. Muscle Activity and Inactivity Periods during Normal Daily Life. PLoS ONE 2013, 8, e52228. [CrossRef] [PubMed]

29. Colyer, S.L.; McGuigan, P.M. Textile Electrodes Embedded in Clothing: A Practical Alternative to Traditional Surface Electromyography When Assessing Muscle Excitation during Functional Movements. J. Sports Sci. Med. 2018, 17, 101-109.

30. Finni, T.; Hu, M.; Kettunen, P.; Vilavuo, T.; Cheng, S. Measurement of EMG Activity with Textile Electrodes Embedded into Clothing. Physiol. Meas. 2007, 28, 1405-1419. [CrossRef] [PubMed]

31. Cohen, J. Statistical Power Analysis for the Behavioral Sciences; Academic Press: Cambridge, MA, USA, 2013; ISBN 978-1-4832-7648-9.

32. Daneshjoo, A.; Rahnama, N.; Mokhtar, A.H.; Yusof, A. Bilateral and Unilateral Asymmetries of Isokinetic Strength and Flexibility in Male Young Professional Soccer Players. J. Hum. Kinet. 2013, 36, 45-53. [CrossRef] [PubMed]

33. Pietraszewski, P.; Gołaś, A.; Matusiński, A.; Mrzygłód, S.; Mostowik, A.; Maszczyk, A. Muscle Activity Asymmetry of the Lower Limbs During Sprinting in Elite Soccer Players. J. Hum. Kinet. 2020, 75, 239-245. [CrossRef] [PubMed]

34. Rahnama, N.; Lees, A.; Bambaecichi, E. A Comparison of Muscle Strength and Flexibility between the Preferred and Non-Preferred Leg in English Soccer Players. Ergonomics 2005, 48, 1568-1575. [CrossRef] [PubMed] 